\title{
Correction to: Role of astrocytic MeCP2 in regulation of CNS myelination by affecting oligodendrocyte and neuronal physiology and axo-glial interactions
}

\author{
L. Buch ${ }^{1}$ J. Langhnoja ${ }^{1}$ P. P. Pillai ${ }^{1}$
}

Published online: 26 October 2018

(c) Springer-Verlag GmbH Germany, part of Springer Nature 2018

\section{Correction to: Experimental Brain Research}

https://doi.org/10.1007/s00221-018-5363-7

In the typesetting of the original version of this article, the Publisher inadvertently confused the first and last names of the authors, leading to their misrepresentation in PubMed. The authors names should read as follows:

Buch L, Langhnoja J and Pillai PP

The original article can be found online at https://doi.org/10.1007/ s00221-018-5363-7.

P. P. Pillai

pillaippp@gmail.com

1 Division of Neurobiology, Department of Zoology, The Maharaja Sayajirao University of Baroda, Vadodara, Gujarat, India 